\title{
Prevalence of Candida infection in Covid-19 pandemic: A study from a tertiary care center in Central India
}

\author{
Saurabh Jayant ${ }^{1}$, Kamlesh Patel ${ }^{2}$, Prachi Priya ${ }^{3}$, Abhilasha Niti Verma ${ }^{4}$, Bharat Singh ${ }^{5}$, \\ Ranjana Dahariya ${ }^{6}$ \\ ${ }^{1}$ Assistant Professor, Department of Microbiology, L.N. Medical College, Bhopal (M.P.), ${ }^{2,5}$ Assistant Professor, \\ Department of Microbiology, Sri Aurobindo Institute of Medical Sciences, Indore (M.P.), ${ }^{3,4}$ Second Year, ${ }^{6}$ Third Year, \\ Post-Graduate Trainee, Department of Microbiology, M.G.M. Medical College, Indore (M.P.)
}

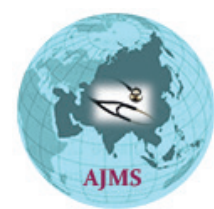

A B S T R A C T

Background: Corona virus disease 2019 (COVID-19) infections may be associated with a wide range of bacterial and fungal co-infections. Candida and mucor are the common fungus encountered during this pandemic. Candida is one of the commonly encountered opportunistic fungi that cause superficial mucosal infections usually, but can invade tissue and produce life threatening infections. Candida species recognized as one of the major agent of hospital Acquired (nosocomial) fungal infections. Keeping this in background the current study was conducted. Aims and Objective: To estimate the prevalence of candida infection in tertiary care hospital of Indore. Materials and Methods: The present study was done in the period of one and half year. During this period all received clinical specimens like urine, sputum; high vaginal swab and pus suspected for fungal infection from Covid as well as non-Covid patients were processed according to standard protocol. The specimen was subjected to preliminary tests like wet mount, Gram's stain, culture on sabourads dextrose agar (SDA) and Hichrome agar, germ tube test, sugar assimilation test and culture on Cornmeal agar (dalmau technique) for candida species were done. For statistical analysis Chi-square test was performed and $p \leq 0.05$ was considered statistically significant. Results: The prevalence of Candidiasis was $0.86 \%$. Non-albicans candida $(65.9 \%)$ isolates was more than Candida albicans (34.07\%). Among non-albicans species, C. tropicalis was $27.4 \%$ followed by $C$. glabrata $16.29 \%$, C. krusei $15.55 \%, C$. parapsilosis $5.92 \%$ and C. lusitenia $0.74 \%$ were the major isolates. Males were affected more than the females. In both the genders maximum patients were from the age group of $>60$ years. Maximum number of Candida isolates was from blood followed by urine, pus, sputum, vaginal swab and aural swab. Most common risk factors for candidiasis noted in this study was diabetes mellitus in both Covid as well as non-Covid patients. Conclusion: Non albicans candida are gradually increasing in India. Speciation of candida play an important role in preliminary treatment because different species is intrinsically resistant to different antifungal drugs and have different antifungal susceptibility pattern.

\section{Access this article online}

Website:

http://nepjol.info/index.php/AJMS DOI: 10.3126/ajms.v12i10.38528 E-ISSN: 2091-0576

P-ISSN: $2467-9100$

Copyright (c) 2021 Asian Journal of Medical Sciences

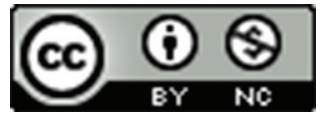

This work is licensed under a Creative Commons Attribution-NonCommercial 4.0 International License.

Keywords: Covid19; Candida albicans; Nosocomial; Non-albicans candida; Candidiasis

\section{INTRODUCTION}

Corona virus disease 2019 (COVID-19) infections may be associated with a wide range of bacterial and fungal co-infections. Candida and mucor are the common fungus encountered during this pandemic. Candida is one of the commonly encountered opportunistic fungi that cause superficial mucosal infections usually, but can invade tissue and can be a source of life threatening infections. ${ }^{1}$ The incidence of fungal infection has increased significantly, contributing to mortality and morbidity. The increasing frequency can be attributed to factors such as the use 
of potent chemotherapeutic agents that alter the host's immune response, the advent of HIV/AIDS, intravenous drug abuse and the success of intensive care unit in prolonging the survival of highly compromised patients. ${ }^{2}$ Candidia albicans is the most common cause of candidiasis, and affect almost all the systems of the body starting from skin to Central nervous system. ${ }^{3}$ Common predisposing factors for Candidiasis are diabetes, malignancy and prolonged use of antibiotics. ${ }^{4}$ Candida also occurs as commensal flora in healthy individuals on mucosal oral cavity, Gastro intestinal tract, vagina etc. With changes in environmental and host conditions this commensal can act as endogenous opportunistic pathogen. The emergence of non-albicans Candida spp. becomes a challenge for clinicians. C.glabrata is less susceptible and Candida krusei is intrinsically resistant to Fluconazole. ${ }^{5}$ C.tropicalis has the highest adherence rate to inanimate materials such as urinary and vascular catheters, and is often involved in biofilm formation, that is more resistant to Antifungal agents. ${ }^{5-7}$ So it becomes an immense important to identify the species of Candida. Speciation of candida play an important role in preliminary treatment because different species is intrinsically resistant to different antifungal drugs and have different antifungal susceptibility pattern which vary from area to area (geographical distribution). ${ }^{6}$ Keeping this in mind, the current study was done to estimate the prevalence of candida infection as well as speciation of candida isolates and to bring out the various risk factors associated with candidiasis.

\section{MATERIALS AND METHODS}

The present study was a prospective cross sectional study done in a tertiary care hospital of Indore (M.P.) from January 2020 to June 2021. This study was pre-approved by the Institutional Ethics Committee (IEC) for the final permission. During this period all received clinical specimens like urine, sputum, high vaginal swab, and pus suspected for fungal infection were processed according to standard protocol. The specimen was subjected to preliminary tests like wet mount, Gram's stain, culture on sabourads dextrose agar (SDA) and Hichrome agar, germ tube test, sugar assimilation test and culture on Cornmeal agar (dalmau technique) for candida species were done. ${ }^{5}$ Gram stain was performed from direct samples and inoculated onto SDA slopes and incubated at $25^{\circ} \mathrm{C}$ and $37^{\circ} \mathrm{C}$ for $24-48$ hours. White to cream-colored, pasty and smooth colonies appeared in within 24 hours to 48 hours. These colonies morphologically resembling the members of genus candida were subjected to Gram staining. On microscopic examination they appeared as Gram-positive budding yeast cells with or without pseudohyphae. Germ tube test was done and the positives were identified as either C.albicans or C.dubliniensis. C.albicans was further identified by growth at $45^{\circ} \mathrm{C}$ and chlamydospore formation on corn meal agar. All the isolates were subjected to sugar fermentation and sugar assimilation tests for final confirmation of the species. Simultaneously the Candida spp. were inoculated onto Hichrom Candida agar (Hi Media Pvt. Ltd, Mumbai) and incubated at $37^{\circ} \mathrm{C}$ for $24 \mathrm{hrs}$ and the species were identified by type and color of the colonies on Hichrom Candida agar as per manufacturer's instructions (Figure-1). Hichrom Candida agar is a novel, differential culture medium that is claimed to facilitate the isolation by colorimetric presumptive identification. ${ }^{8}$ Statistical analysis was carried out for 135 Candida isolates associated with various risk factors including Covid. The association was analyzed using Chi-square test. $\mathrm{P}$ value $\leq 0.05$ was considered statistically significant. Microsoft Excel 2000 (version 9) and SPSS (Statistical Package for Social Sciences) Version 22.0 software was used for data entry and analysis.

\section{RESULTS}

In this study total no of 15559 various clinical specimens were processed and total candida species isolated were 135. The prevalence of Candidiasis was $0.86 \%$ (Table- 1 ).

Non-albicans candida (65.9\%) isolates was more than Candida albicans (34.07\%), (Table-2). Among non-albicans species, C. tropicalis was $27.4 \%$ followed by C. glabrata $16.29 \%, C$. kerusei $15.55 \%$, C. parapsilosis $5.92 \%$ and C. lusitenia $0.74 \%$ were the major isolates (Table-2).

Maximum number of Candida isolates was from blood followed by urine, pus, sputum, vaginal swab and aural swab (Table-3). C.albicans and C.krusei was the major isolates from blood while C.tropicalis and C. glabrata was the major isolates from urine. C.parapsilosis was the major isolate from aural swab while single isolate of C.lusitenia isolated from oral thrush (Table-3). However, statistical analysis with

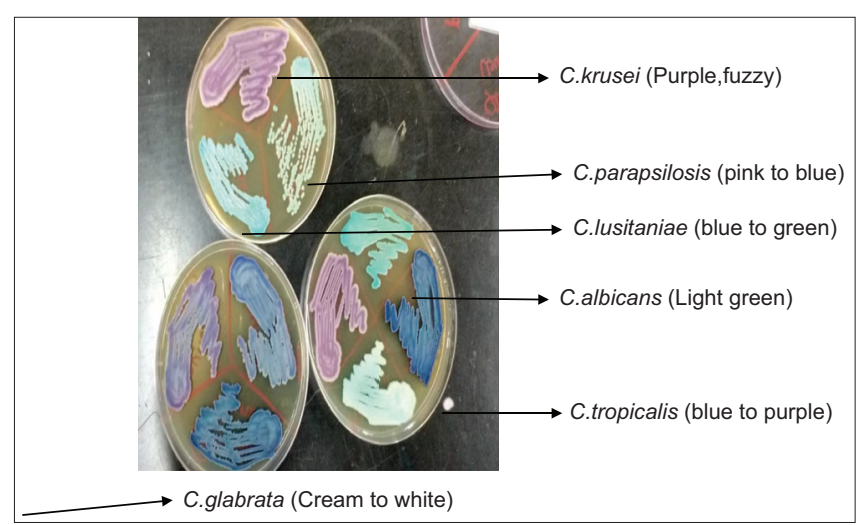

Figure-1: Appearance of different species of candida on Hichrome candida agar 
Chi square test does not reveal any significant trend in distribution with $\mathrm{P}>0.05(\mathrm{P}=0.125)$.

Candida isolates was found to be higher in male patients $(52.5 \%)$ as compared to female patients $(47.4 \%)$ (Table-4).

Maximum no of isolation of Candida species was in the age group above 60 years $(39.2 \%)$ (Table-5).

Covid was an important risk factor to acquire the opportunistic candida infection. Patients with diabetes (includes both Covid and non-Covid) had prevalence rate of $31.8 \%$ while only Covid along with diabetes had

\begin{tabular}{lcc}
\multicolumn{3}{l}{$\begin{array}{l}\text { Table 1: Prevalence of Candida species in various } \\
\text { clinical specimens }\end{array}$} \\
\hline Clinical specimen & $\begin{array}{c}\text { Total no sample } \\
\text { screened }\end{array}$ & $\begin{array}{c}\text { No of candida } \\
\text { species Isolated }\end{array}$ \\
\hline Blood & 3474 & 26 \\
Urine & 3126 & 23 \\
Pus & 2713 & 19 \\
Sputum & 1287 & 15 \\
Vaginal swab & 1254 & 15 \\
Aural swab & 1646 & 13 \\
Endotracheal aspirate & 555 & 9 \\
Oral thrush & 45 & 5 \\
Throat swab & 1350 & 6 \\
Juglar tip & 54 & 1 \\
Corneal scrappings & 55 & 3 \\
Total & 15559 & 135 \\
\hline
\end{tabular}

\begin{tabular}{lcc}
$\begin{array}{l}\text { Table 2: Distribution of candida species in } \\
\text { clinical specimens }\end{array}$ & \\
\hline Different Species & Total isolates & Percentage (\%) \\
\hline C.Albicans & 46 & 34.07 \\
C.Tropicalis & 37 & 27.40 \\
C.Glabrata & 22 & 16.29 \\
C.Krusei & 21 & 15.55 \\
C.Parapsilosis & 8 & 5.92 \\
C.Lusitenia & 1 & 0.74 \\
Total & 135 & 100 \\
\hline
\end{tabular}

prevalence rate of $32.6 \%$. Diabetes mellitus followed by use of broad-spectrum antibiotics and steroids were the common risk factor associated with candidiasis in both Covid as well as non-Covid patients. Patients on chemotherapy, indewelling Foleys catheter, Pregnancy and long term ICU stay were the other risk factors associated with candidiasis in non-Covid patients only (Table-6).

Statistical analysis with Chi square test reveal significant association of risk factors like diabetes mellitus, use of broad spectrum antibiotics, patient on chemotherapy, urinary catheterization and vaginitis/pregnancy with $\mathrm{P}<0.05$. That is the results were found to be highly significant.

\section{DISCUSSION}

Studies over the years have shown that there is a considerable increase in the prevalence non-candida albicans (NAC) species. In this study NAC in all clinical specimens were $65.9 \%$ which were frequently encountered than C. albicans $(34.7 \%)$, which was in agreement with the findings by Shivanand et al., Ragini et al., Manchanda et al. and Vijaya et al., who also showed the NAC incidence to be higher than that of C. albicans. ${ }^{9-12}$ In our study nonalbicans, Candida tropicalis were $27 \%$ which was similar to study conducted by Ragini et al., and Chakrabarthi et al. ${ }^{10,13}$

In our study candida isolates was found to be higher in male patients $(52.5 \%)$ as compared to female patients (47.4\%). This correlates with the study done by R A Kashid et al., ${ }^{18}$ males 55.10\% while females 44.8\% and Arasi Samyuktha A et al., ${ }^{14}$ male $51.2 \%$ while female $48.8 \%$. But differed from Amar C S et al., who isolated Candida species more from female $(60.2 \%)$ than male $(39.8 \%)$ patients. ${ }^{19}$ In our study maximum number of isolation of Candida species was in the age group above 60 years $(39.2 \%)$ which was similar to

\begin{tabular}{|c|c|c|c|c|c|c|c|}
\hline $\begin{array}{l}\text { Isolated candida } \\
\text { species }\end{array}$ & $\begin{array}{l}\text { Candida } \\
\text { tropicalis }\end{array}$ & $\begin{array}{l}\text { Candida } \\
\text { albicans }\end{array}$ & $\begin{array}{l}\text { Candida } \\
\text { parapsilosis }\end{array}$ & $\begin{array}{l}\text { Candia } \\
\text { krusei }\end{array}$ & $\begin{array}{l}\text { Candida } \\
\text { glabrata }\end{array}$ & $\begin{array}{l}\text { Candida } \\
\text { Iusitanea }\end{array}$ & Total \\
\hline Blood & 6 & 10 & 1 & 7 & 2 & 0 & 26 \\
\hline Urine & 6 & 9 & 0 & 4 & 4 & 0 & 23 \\
\hline Pus & 4 & 10 & 1 & 2 & 2 & 0 & 19 \\
\hline Sputum & 6 & 3 & 1 & 3 & 2 & 0 & 15 \\
\hline Vaginal swab & 6 & 3 & 0 & 2 & 4 & 0 & 15 \\
\hline Aural swab & 3 & 3 & 3 & 1 & 3 & 0 & 13 \\
\hline Entotracheal secretion & 2 & 4 & 2 & 0 & 1 & 0 & 9 \\
\hline Oral thrush & 2 & 1 & 0 & 0 & 1 & 1 & 5 \\
\hline Throat swab & 1 & 2 & 0 & 1 & 2 & 0 & 6 \\
\hline Jugular tip & 0 & 1 & 0 & 0 & 0 & 0 & 1 \\
\hline Corneal scrapping & 1 & 0 & 0 & 1 & 1 & 0 & 3 \\
\hline Total & 37 & 46 & 8 & 21 & 22 & 1 & 135 \\
\hline
\end{tabular}


Table 4: Gender wise distribution of candida isolates

\begin{tabular}{lcc} 
Gender & Number of candida isolated & Percent (\%) \\
\hline Male & 71 & 52.5 \\
Female & 64 & 47.4 \\
Total & 135 & 100 \\
\hline
\end{tabular}

Table 5: Age wise distribution of the study population

\begin{tabular}{lcc} 
Age (years) & Number of cases & Percent(\%) \\
\hline $0-10$ & 11 & 8.1 \\
$10-20$ & 05 & 3.7 \\
$20-30$ & 03 & 2.2 \\
$30-40$ & 12 & 8.8 \\
$40-50$ & 17 & 12.5 \\
$50-60$ & 34 & 25.1 \\
$>60$ & 53 & 39.2 \\
Total & 135 & 100 \\
\hline
\end{tabular}

\begin{tabular}{|c|c|c|c|c|c|c|}
\hline \multirow[t]{2}{*}{ Predisposing factor } & \multicolumn{3}{|c|}{ Number of candida isolates } & \multirow[t]{2}{*}{ Percentage } & \multirow[t]{2}{*}{$P$ value } & \multirow[t]{2}{*}{ Association } \\
\hline & $\begin{array}{l}\text { Covidpositive } \\
(\mathrm{n}=38)\end{array}$ & $\begin{array}{l}\text { Covidnegative } \\
(\mathrm{n}=97)\end{array}$ & $\begin{array}{c}\text { Total } \\
(n=135)\end{array}$ & & & \\
\hline Diabetes mellitus & 14 & 29 & 43 & 31.85 & 0.02 & Significant \\
\hline Broad spectrum antibiotics & 10 & 22 & 32 & 23.70 & 0.03 & Significant \\
\hline Steroids & 14 & 10 & 24 & 17.77 & 0.41 & Insignificant \\
\hline Patient on chemotherapy & 00 & 17 & 17 & 12.59 & 0.00003 & Significant \\
\hline Urinary catheterization & 00 & 12 & 12 & 8.88 & 0.0005 & Significant \\
\hline Vaginitis/pregnancy & 00 & 05 & 05 & 3.70 & 0.03 & Significant \\
\hline ICU stay and intravenous juglar tip & 00 & 02 & 02 & 1.48 & 0.15 & Insignificant \\
\hline
\end{tabular}

the report from the studies conducted by Arasi Samyuktha A et al., ${ }^{14}$ and Kashid et al. ${ }^{18}$ who also reported highest incidence in the age group above 60 years $(24.4 \%)$. In our study we found that diabetes mellitus was most important risk factor associated with candida infection $(31.8 \%)$ which was similar to the study of Arasi Samyuktha A et al. ${ }^{14}$ In our study highest prevalence rate of candida was maximum from blood samples (19.2\%). A New Delhi based study gave a prevalence rate of candida from blood sample were 18\% while a study in South India reported an prevalence rate of $5.7 \%{ }^{15,16}$ Study conducted by Sahni et al. from Maulana Azad Medical College, New Delhi, found an prevalence rate of $6.9 \%$ for Candida species in BSI. ${ }^{17}$ These studies suggest wide variations in the prevalence of candidemia in different geographical location of India. In our study we found that the candida infection in ear discharge were $9.62 \%$, In a clinical study done by Ram Kumar et al., ${ }^{8}$ the incidence of tympanic membrane perforation especially in immunocompromised patients was found to be $11 \%$ which was similar to our study. In our study $3.70 \%$ women with vaginitis/pregnancy affected with candidiasis In other study conducted by Vijaya D et al., ${ }^{12}$ reported $10 \%$ pregnant women with candidiasis. The increased incidence of vaginal candidiasis in pregnant women may be due to elevated levels of progesterone and estrogen. In the present study patients with diabetes had prevalence rate of $31.8 \%$, which was noted to be higher than the study reported by Kamali et al., (17\%). In this study Covid along with diabetes have a high prevalence rate of $32.6 \%$ which was similar to the study of J. Katz. ${ }^{20}$ Covid play as game changer role because it interfere with T cells causing decreased immunity leading to opportunistic candida infection. ${ }^{20}$ Analyses have reported vulnerability of immune-compromised patients with preexisting comorbidities e.g. diabetes, excessive use of broad spectrum antibiotics and steroids towards candidiasis. Diabetes and uncontrolled glycaemia were reported as significant predictors of severity in Covid patients. ${ }^{20}$

\section{CONCLUSION}

The prevalence of Candidiasis was $0.86 \%$. Non-albicans candida $(65.9 \%)$ isolates was more than Candida albicans (34.07\%). Among non-albicans species, C. tropicalis was $27.4 \%$ followed by C. glabrata $16.29 \%$, C. krusei $15.55 \%$, C. parapsilosis $5.92 \%$ and C. lusitenia $0.74 \%$ were the major isolates. Males were affected more than the females. In both genders maximum patients belong to the age group of $>60$ years. Maximum number of Candida isolates was from blood followed by urine, pus, sputum, vaginal swab and aural swab. Most common risk factors for candidiasis 
noted in this study was diabetes mellitus in both Covid as well as non-Covid patients.

\section{REFERENCES}

1. Ruhnke M and Maschmeyer G. Management of mycoses in patients with hematologic disease and cancer-review of the literature. European Journal of Medical Research. 2002; 7 (5): 227-235.

2. Khan ZK and Gyanchandani A. Candidiasis: a review. PINSA B64 No.1 1998; 1-34.

3. Jarwis B. Epidemiology of nosocomial fungal infections with emphasis on candida species. Clin infect Dis. 1995; 20:1526-1530.

4. Kamali M, Sarvtin MT and Parsanasab H. Prevalence of candida infection in patients with Type 2 Daibetes Mellitus in Sari, North of Iran. Biomed Pharmacol J. 2016:9(2).

5. Segal E, Elad D. Candidiasis. In: Merz WG, Hay RJ,Topley Wilson's - Microbiology and microbial infection. $10^{\text {th }}$ ed. Medical mycology: London: Hodder Arnold; 2007: 579-613.

6. Arora D, Anand N, Goya G, Kumar R and Gupta P, Santa. Prevalence and risk factors of Candida in cases of candidemia in a tertiary care hospital. International journal of pharmacy and pharmaceutical sciences. 2011; 3(1): 157-159.

7. Kurtzman CP and Fell JW. (2006) Yeasts Systematics and Phylogeny-Implication of Molecular Identification Methods for Studies in Ecology. In: Péter, G. and Rosa, C., Eds., Biodiversity and Ecophysiology of Yeasts, Springer, Berlin, 11-30.

8. Kumar KR. Silent perforation of tympanic membrane and otomycosis. Indian Journal of Otolaryngology. 1984; 36(4):161-162.

9. Shivanand D and Saldanha DRM. Species identification of Candida isolates in various clinical specimens with their anti-fungal susceptibility patterns. J Clin Diag Res. 2011; 5(6):1177-1181.

10. Ragini AK, Sandhya B and Indumal G. Characterisation and antifungal susceptibility testing for Candida in tertiary care hospital. J Health Sci Res. 2011; 2(2):1-12.

11. Manchanda V, Agarwal S and Verma N. Yeast identification in routine clinical microbiology laboratory and its clinical relevance. Ind J Med Microbiol. 2011; 29(2):172.

12. Vijaya D, Harsha TR and Nagaratnamma T. Candida speciation using CHROM agar. J Clin Diagn Res. 2011; 5(4):755-757.

13. Chakrabarthi A, Ghosh A, Batra R, Kaushal A, Roy P and Singh $\mathrm{H}$. Antifungal susceptibility on non-Candida albicans and distribution of species isolated from Candidaemia cases over a 5-year period. Indian J Med Res.1996; 104:171-176.

14. Arasi Samyuktha $A$ and Chitralekha S. Isolation, Identification and Speciation of Candida Species from Various Clinical Specimens in a Tertiary Care Hospital in Chennai. Sch J App Med Sci. 2017; 5(8F):3460-3468.

15. Kothari A and Sagar V. Epidemiology of Candida bloodstream infections in a tertiary care institute in India. Indian J Med Microbiol. 2008; 27: 171-172.

16. Kumar CP, Sundararajan T, Menon T and Venkatadesikalu M. Candidiosis in children with onco-hematological diseases in Chennai, south India. Jpn J Infect Dis. 2005; 58: 218-221.

17. Sahni V, Agarwal SK, Singh NP, Anuradha S, Sikdar S, Wadhwa A, et al. Candidemia - an under-recognized nosocomial infection in Indian Hospitals. J Assoc Physicians India. 2005; 53: 607-611.

18. Kashid RA, Belawadi S, Devi G and Dadich D. Characterization and antifungal susceptibility testing for Candida species in a tertiary care hospital. J Health Sci Res. 2011; 2(2):1-7.

19. Amar CS, Ashish J, Hajare $V$ and Belagali Y. Study of prevalence and antifungal susceptibility of candida. International Journal of Pharma and Bio Sciences. 2013; 4(2):361-381.

20. Katz J. Prevalence of candidiasis in COVID-19 patients: a crosssectional pilot study from the patients' registry in a large health center. Quintessence Int. 2021; 52(8):714-718.

\section{Author's Contribution:}

SJ, KP-Concept and design of the study, prepared first draft of manuscript; PP, AV, RD- coordination; reviewed the literature and manuscript preparation; BS- Concept, coordination, Interpretation of results, preparation of manuscript and revision of the manuscript.

\section{Work Attributed to:}

Sri Aurobindo Institute of Medical Sciences, Indore (M.P.).

Orcid ID:

Dr. Saurabh Jayant- (1) https://orcid.org/0000-0003-2450-9971

Dr. Kamlesh Patel- (1) https://orcid.org/0000-0002-1123-916X

Dr. Prachi Priya- (D) https://orcid.org/0000-0003-4037-1589

Dr. Abhilasha Niti Verma- (i) https://orcid.org/0000-0001-9979-2017

Dr. Bharat Singh- (1) https://orcid.org/0000-0001-6762-5943

Dr. Ranjana Dahariya- (D) https://orcid.org/0000-0003-4359-4489

Source of Funding: None, Conflicting Interest: None. 